\title{
Determinants of Tax Compliance: A Case of Nekemte Town Category 'C' Business Profit Tax Payers
}

\section{Dereje Birhanie Jemberie}

Department of Accounting and Finance, College of Business and Economics, Debre Markos University, Debre Markos, Ethiopia

Email address:

Acc12321dar@gmail.com

\section{To cite this article:}

Dereje Birhanie Jemberie. Determinants of Tax Compliance: A Case of Nekemte Town Category 'C' Business Profit Tax Payers. International Journal of Economics, Finance and Management Sciences. Vol. 8, No. 3, 2020, pp. 89-97. doi: 10.11648/j.ijefm.20200803.11

Received: March 24, 2020; Accepted: April 28, 2020; Published: June 3, 2020

\begin{abstract}
This study is designed to investigate the determinants of tax compliance in a case of category " $\mathrm{C}$ " business profit taxpayers in Nekemte town. To achieve the designed objectives the study employed a quantitative approach. Necessary data for the study were gathered via questionnaire and reviewing necessary documents. To do this the researcher took out 346 samples from the total 2580 population size of category "c" taxpayers and analyzed the returned 240 questions. The sample size of the study was determined by using simple random sampling technique. Responses of respondents were presented by using the data presentation tools and analyzed via STATA 10 software application and descriptive analytical methods using tables and charts. The study found that, family size and length of tax payment period has a significant negative influence on tax compliance. On the other hand, tax knowledge and awareness and tax penalty and fines has a significant positive influence over the level of tax compliance. The assessed amount of tax, probability of auditing and attitudes towards equity and fairness are insignificant factors in determining the compliance behavior of taxpayer. Finally the researcher recommended that different job opportunities and incentives should be provided by the authorized body to increase earning of large size family members. ERCA should be follow up taxpayers and control their activities to easily prevent evasion by taxpayers; and sufficient and adequate training, awareness creation and education should be offered to taxpayers to enhance their knowledge regarding to tax. Besides ERCA should take measures and penalties on those taxpayers who are not willing to pay their tax liability within a specified time period for the purpose of generating more revenues.
\end{abstract}

Keywords: Assessed Amount of Tax, Length of Tax Payment Period, Tax Compliance, Taxpayers, Penalty

\section{Introduction}

Tax refers to a compulsory levy in which every citizen of the country are required to pay for the government without receiving a direct benefit. So, Taxation is a system of rising money to finance government expenditure for the purpose of maximizing social welfare. The government uses the tax that is collected from the people as revenue to pay salary to soldier, police, to build dams and roads, and hospitals, generally to provide goods and services that are essential to the society [1].

The amount of revenue generated by government from such taxes payers for its expenditures depends among other factors, on the willingness of the taxpayers to voluntarily comply with tax laws. The failure to follow the provisions of the tax implies that the taxpayer may be committing an act of noncompliance. Tax non-compliance occurs through failure to file tax return, misreporting income ormisreporting allowable subtractions from taxable income or tax due [2].

According to [3] tax compliance is a complex term to define. Simply, tax compliance refers to fulfilling all tax obligations as specified by the tax law freely and completely.

Reference [4] Define tax compliance as the degree to which a taxpayer complies or fails to comply with the tax rules of their country. The objective of an efficient tax administration in any country is to ensure voluntary tax compliance using any legal means possible which may also involve the use of sanctions.

Reference [5] On their research reflects that the degree of non-compliance which may be expressed in terms of the tax gap; which is the deviation between the actual revenue collected and the amount that would be collected if there were 100 per cent compliance. There is the question whether 
'compliance' refers to voluntary or compulsory behavior. If taxpayers 'comply' only because of dire threats or harassment or both, this would not appear to be proper compliance even if 100 per cent of the tax were raised in line with the tax gap concept of noncompliance. Instead, it might be argued that successful tax administration requires taxpayers to comply willingly, without the need for enquiries, obtrusive investigations, reminders or the threat or application of legal or administrative sanctions.

\subsection{Statement of the Problem}

Taxation is an important source of revenue to government in both developing and developed countries to provide the basic infrastructural facilities and raise social welfare. The government of Ethiopia also obtains a huge amount of revenue from taxation; which is helpful to provide public goods and services for the welfare of the society as a whole. This objective can be achieved only when all taxpayers are voluntarily comply with the tax laws, regulations and procedures and have an interest to improve the society. However, taxpayers are not interested to comply with tax system. Tax non-compliance behavior is reflected in schedule $\mathrm{B}, \mathrm{C}, \& \mathrm{D}$ income, and from schedule ' $\mathrm{C}$ ' mostly in category ' $C$ ' taxpayers since the method of assessment is on estimation. So, enhancing voluntary tax compliance of taxpayers must be a primary task of every revenue authorities. To narrow the gap between budgeted amount of tax to be collected and actually collected amount of tax it is better to understand the critical factors which determine the level of compliance. Tax non-compliance by taxpayers is a serious problem for administrating business and rental income tax revenue in Ethiopia, and some other developing countries. There were studies done on tax compliance in Ethiopia. [6] on their research entitled as "Determinants of Voluntary Tax Compliance Behavior in Self -Assessment System: Evidence from SNNPRS, Ethiopia tried to investigate the determinants of compliance levels of taxpayers. Even if different studies were conducted in different places and at different time to cure the non-compliance behavior of tax payers; to the best of the researchers knowledge the issues are not well understood and still unsolved and needs further studies. In addition, while reviewing the related literatures, they found inconclusive results on the determinants of tax compliance. Still tax payers are not voluntarily pay tax every year and try to evade tax by using their secret means. Hence, the above research gap motivated the researcher to identify and examine the determinants of voluntary compliance behavior of tax payers in category " $\mathrm{C}$ " taxpayers of Nekemte town.

\subsection{Research Questions}

1) Do individual factors have a significant effect on the level of compliance?

2) Does an institutional factor significantly affect tax compliance?

3) Does the psychology of taxpayers have a significant effect on tax compliance?

\subsection{Objective of the Study}

\subsubsection{General Objective}

The general objective of the study is to investigate the determinants of tax compliance on category " $\mathrm{C}$ " tax payers of Nekemte town.

\subsubsection{Specific Objective of the Study}

1) To examine the effect of individual factors on the level of tax compliance

2) To evaluate the effect of institutional factors on tax compliance

3) To evaluate the effect of psychological factor on tax compliance

\subsection{Research Hypothesis}

The hypotheses of the research which were formulated and tested are:

$\mathrm{H}_{\mathrm{a}}$ 1: The family size of the taxpayer has a significant effect on tax compliance

$\mathrm{H}_{\mathrm{a}}$ 2: The level of tax knowledge and awareness has a significant effect on tax compliance

$\mathrm{H}_{\mathrm{a}}$ 3: Length of tax payment period has a significant effect on the levels of tax compliance

$\mathrm{H}_{\mathrm{a}} 4$ : The assessed amount of tax has a significant effect on tax compliance

$\mathrm{H}_{\mathrm{a}}$ 5: The probability of auditing by ERCA has a significant effect on tax compliance

Ha6: Tax penalty and fines has a significant effect on the level of tax compliance

$\mathrm{H}_{\mathrm{a}}$ 7: Perception of equity and fairness on tax a significant effect on the level of compliance

\section{Review of Related Literature}

\subsection{Empirical Literature Review}

Compliance behavior of taxpayers may be affected by many factors. Those factors that influence tax compliance behavior are varied from one country to another country and from one individual to another individual [7].

On a study by the study [8] entitled 'Factors that affect tax compliance among small and medium enterprises' in Northern Central Nigeria found some of the critical factors which has a significant effect on taxpayers compliance behavior. They collect the data for their research from primary sources using survey method of 150 respondents of small and medium enterprises. On their research they found that high tax rates, complex filing procedures, multiple taxation and lack of proper enlightenment are the factors which affect tax compliance among small and medium enterprise taxpayers.

References [9] were undertook a study on a title 'Factors that influence rental taxpayers compliance with the tax system: an empirical study of Mekelle City, Ethiopia by distributing structured questioners for 140 respondents. On their study they found that the major problems of rental tax compliance in Mekelle City, Ethiopia were intentional tax 
avoidance (presence of dishonest taxpayers), that means some rental taxpayers deliberately understate their taxable income, and also there are some individuals who entirely do not report their taxable income to the concerned body. Consequently, it has an influence on the attitudes and tax compliance behavior of taxpayers towards the tax system. Besides, lack of awareness on tax related issues, and low awareness creation by the Revenue and Tax Authority of Mekelle City to taxpayers were found to be the major factors for tax compliance issues.

On a study entitled as 'Evaluating taxpayers attitude and its influence on tax compliance decisions in Tamale, Ghana' by the study [10] focused on individual self-employed/petty traders and individuals engaged in small and medium scale enterprises. After critically analyzing the survey they found that individuals are highly concerned with the amount of taxes they pay to the tax revenue office. The income tax rates which are applicable in Ghana are generally considered to be high. Besides, the burden of taxes paid by taxpayers affects their attitudes and this informs how they evaluate the tax system and consequently their compliance decisions. In addition to that of the tax rates; other factors which influences the tax compliance behavior of individuals were individual perception level for the benefits which is derived from public goods and services provided by the government, poor understanding of the tax laws, and levels of accountability and transparency in governance are factors that tax payers have less regard for their tax compliance issues.

Reference [11] was conducted a study on a title 'Determinants of tax compliance by small and medium enterprises' in Zimbabwe can be summarized as follows: The main objectives of the study were to investigate how the unique business conditions of small and medium enterprises, the perceptions of small and medium operators towards taxation, levels of tax knowledge and compliance costs affect tax compliance of small and medium enterprise taxpayers. To achieve these objectives, the researcher stated research propositions: the current tax system in Zimbabwe does not cater for the special business needs of small and medium enterprises and that strong correlation do exist among tax knowledge, compliance costs, and tax compliance. The results indicated that small and medium enterprises face different business conditions from large companies which cause them to bear high tax compliance burdens. The results also indicated that the perceptions of small and medium enterprise operators about tax fairness, tax service quality and government spending priorities greatly affect their tax compliance decisions. Tax knowledge was discovered to have no correlation with tax registration compliance but week negative correlations with filing compliance.

There was a study conducted by the study [12] on "determinants of tax compliance behavior in Ethiopia: the case of Bahir Dar City taxpayers and he summarized the findings as follows: the researchers used quantitative methods research approach to investigate the factors affecting tax compliance. The researchers also employed survey methods of data collection using questionnaires. They analyzed the collected data from 201 sample respondents through the use of T-test and one-way ANOVA. The results revealed that perception of government spending, perception of equity and fairness of the tax system, penalties, personal financial constraint, changes on current government policies and referral group (friends, relatives, etc.) are factors that significantly affect tax compliance behavior of taxpayers. However gender and probability of being audited have no significant impact on tax compliance behavior. The findings also showed that older people will comply less if there is no equity and fairness in the tax system and any changes in government policy on fuel prices, electricity and water rates are not favorable.

A research conducted by the study [13] on a title 'Factors Affecting Tax Compliance of Small and Medium Business Profit Taxpayers in Addis Ababa' can be summarized as follows. The researcher used a descriptive survey design to study the factors that affect the tax compliance behaviors of tax payers. To achieve his objective he employed survey method and key informant interview of 230 sample respondents from small and medium business enterprise. The study revealed that factors included social services, tax compliance costs, knowledge of tax rules and procedures; attitude towards tax and services of the ERCA to the taxpayers has a significant influence on tax compliance of small and medium enterprise taxpayers.

Reference [6] were undertook a study entitled as 'Determinants of Voluntary Tax Compliance Behavior in Self Assessment System: Evidence from SNNPRS, Ethiopia' by distributing 310 self-administered questionnaire. According to the finding level of tax compliance is significantly influenced by tax knowledge, perception of tax payers towards government spending, tax rates, tax payer's perception towards equity and fairness, educational level of tax payers, tax penalty and the role of tax authority. Their study also evidenced that, other variables such as penalty, role and efficiency of tax authority, tax rates, personal financial constraint of respondents, age and gender of respondents were not significant determinants of tax compliance behavior in SAS.

On a study conducted by the study [14] on 'Factors affecting voluntary compliance of category ' $c$ ' taxpayers' attitude of Arbaminch, SNNPR, Ethiopia'. The researchers employed descriptive research design. To collect the data from 81 sample respondents they used self -administered questionnaire. In effect the study indicated that the factors which affect the taxpayers' voluntary compliance behavior can be concluded as the tax rate undoubtedly higher than what most taxpayers would like it to be. Most of the respondents feel that people should pay taxes according to their ability; in other words they feel that they do not pay the same amount of tax as others in similar situations. The survey data has showed that majority of the taxpayers know why they pay taxes but they have no detail knowledge about taxation. So lack of awareness was quoted as the major and leading reason for nonexistence of voluntary compliance among category ' $\mathrm{C}$ ' tax payers in Arba Minch city. 


\subsection{Conceptual Framework}

This study conceptualizes that, the tax compliance could be affected by assessed amounts of tax, family size, length of tax payment period, perceptions of fairness and equity, probability of auditing, tax knowledge and awareness and fines and penalties. The purpose of this study is therefore to test the nature and the strength of these relationships. This study tests the conceptual framework presented in figure 1.

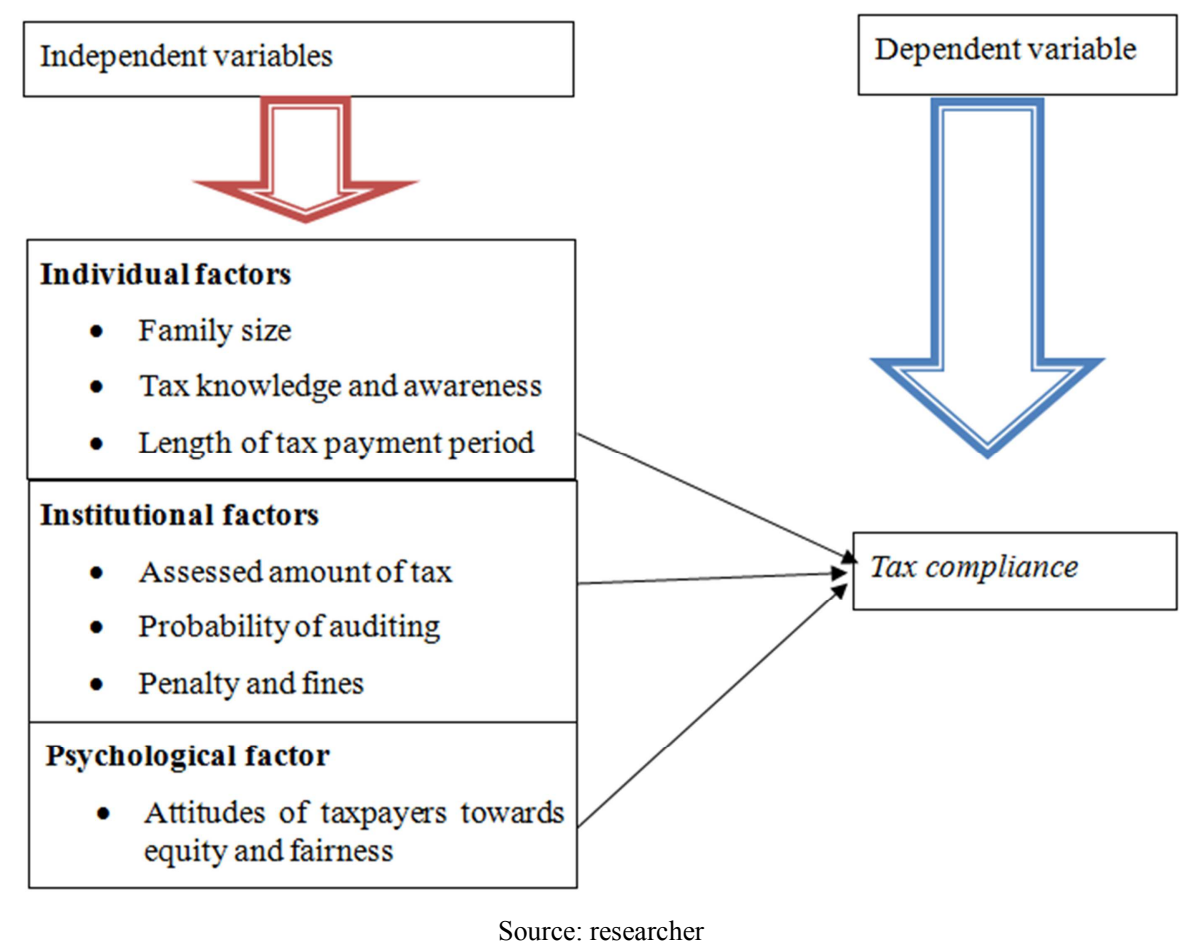

Figure 1. Conceptual framework.

\section{Research Method}

\subsection{Research Design}

The study used a descriptive research design aimed at describing the relevant facts. In meeting the study objectives', the researcher used a mixed research approach. This approach is characterized by much greater control over the research environment and in this case some variables were manipulated to observe their effect on other variables. The necessary financial resource was obtained from the ministry of education.

\subsection{Types and Sources of Data}

In this study the researcher used both primary and secondary data. Primary data were gathered from primary data source and secondary data were gathered from secondary data source. The relevant sources for primary data were sample respondents of category " $C$ " tax payers found in Nekemte town. Secondary data were collected from office reports, documents and articles.

\subsection{Data Collection Tools}

Relevant data which are helpful to undertake this research were collected through primary data collection tools and secondary data collection tools. Primary data were collected through close ended questionnaires. Close ended questionnaires were prepared in the form of five LikeretScale, those are; strongly Agree $(\mathrm{SA})=5$; Agree $(\mathrm{A})=4$; Neutral $(\mathrm{N})=3$, Disagree (D) $=2$; and Strongly Disagree (SD) $=1$; this helps to make it easier for respondents to answer question in an easy means.

\subsection{Target Group and Sampling Design}

In this study category " $\mathrm{C}$ " business profit taxpayers found in East Wollega zone; Nekemte town are the target groups, those are 2,580 in number. Sample respondents have been selected from the population by using probability sampling method, simple random sampling technique. The sample size of taxpayers was determined by using sample determination formula developed by the study [15]: $\mathrm{n}=\mathrm{N} / 1+\mathrm{N}\left(\mathrm{e}^{2}\right)$. Based on this sample determination formula the sample size for the study calculated as follows:

$$
\begin{gathered}
n=\frac{N}{1+N(e)^{2}} \\
\mathrm{n}=2580 /\left(1+2580(0.05)^{2}\right) \\
\mathrm{n}=346
\end{gathered}
$$

Where: N- population; n- Sample size; e- Margin of error

\subsection{Model Specification}

To undertake this research the researcher used an econometric model called logit distribution function model. 
The model of the study is presented as follows:

$$
\begin{gathered}
\mathrm{Pi} / 1-\mathrm{pi}=\mathrm{e}^{\mathrm{zi}} \\
\mathrm{Li}=\ln (\mathrm{pi} / 1-\mathrm{pi})=\mathrm{zi}=\beta_{0}+\beta 1 \mathrm{Xi}
\end{gathered}
$$

$$
\mathrm{Pi}=1 / 1+\mathrm{e}^{(\beta 0+\beta 1 \mathrm{xi})}
$$

$$
\mathrm{Yi}=\beta_{0}+\beta_{1} \mathrm{AAT}+\beta_{2} \mathrm{FS}+\beta_{3} \mathrm{LTPP}+\beta_{4} \mathrm{ATEF}+\beta_{5} \mathrm{POA}+\beta_{6} \mathrm{TKA}+\beta_{7} \mathrm{PF}+\varepsilon \mathrm{i}
$$

$\mathrm{Yi}=1$; if tax payers is compliant, 0 if the tax payer is notcompliant.

$\beta_{0}$ - represents intercept

$\beta$ - Vector of estimated parameters.

$\varepsilon \mathrm{i}$ - error terms which represents the factors that affect tax compliance outside explanatory variables.

So, tax compliance is a dependent variable which is explained by those seven explanatory/independent variables.

Assessed amount of tax-AAT

Family size-FS

Length of tax payment period-LTPP

Probability of auditing-POA

Attitude towards equity and fairness-ATEF

Tax knowledge and awareness-TKA

Tax penalty and fine-TPF

\subsection{Methods of Data Analysis}

Data that are obtained from primary and secondary data source were presented through table, and charts and it were analyzed through the use of inferential statistics. Binary logistic regression model have been used to explain the effects of independent variables on dependant variable.
Different tests regarding to the model were done.

\section{Results and Discussions}

This chapter presents, analyzes and interprets the results of the study based on the formulated objectives and hypotheses that are presented in chapter one. In order to perform the task questionnaires were distributed to sample taxpayers. A total of 346 questionnaires were distributed to Category "C" taxpayers, of whom 240 returned and filled completely and properly. This made the response rate of approximately $70 \%$. In this chapter, firstly model estimation is made. Secondly, different tests are involved for the fitness of the model and results are analyzed and discussed. Finally the formulated hypothesis for each variable in chapter one is tested.

\subsection{Regression Analysis}

To show the effects and relationships of independent variables on the dependant variables the researcher used

\begin{tabular}{|c|c|c|c|c|c|}
\hline TC & Coef. & St.Err & t-value & p-value & Sig. \\
\hline AAT & -0.000000485 & 0.000 & -0.25 & 0.805 & \\
\hline FS & -0.919 & 0.228 & -4.03 & 0.000 & $* * *$ \\
\hline LTPP & -1.194 & 0.216 & -5.52 & 0.000 & $* * *$ \\
\hline POA & 0.079 & 0.200 & 0.39 & 0.694 & \\
\hline ATEF & 0.020 & 0.175 & 0.11 & 0.911 & \\
\hline TKA & 0.731 & 0.181 & 4.04 & 0.000 & $* * *$ \\
\hline $\mathrm{PF}$ & 0.365 & 0.171 & 2.14 & 0.032 & $* *$ \\
\hline _cons & 4.632 & 1.480 & 3.13 & 0.002 & \\
\hline $\bar{P}_{\text {Pseudo r-squared }}$ & \multicolumn{2}{|l|}{0.612} & \multicolumn{2}{|c|}{ Number of obs } & 240.000 \\
\hline Chi-square & \multicolumn{2}{|l|}{194.914} & \multicolumn{2}{|c|}{ Prob > chi 2} & 0.000 \\
\hline Akaike crit. (AIC) & \multicolumn{2}{|l|}{139.640} & \multirow{2}{*}{\multicolumn{2}{|c|}{ Bayesian crit. (BIC) }} & 167.486 \\
\hline$* * * \mathrm{p}<0.01, * * \mathrm{p}<0$ & & & & & \\
\hline
\end{tabular}
binary logistic regression model. The regression result reflected in the following table.

Table 1. Binary logistic regression.

Source: Stata 10

As indicated in the above table, the regression result with the coefficient of determination (pseudo $\mathrm{R}^{2}$ ) of 0.6119 shows that $61.119 \%$ of changes in tax compliance is determined by the independent variables viz. assessed amount of tax (AAT), family size (FS), length of tax payment period (LTPP), attitudes towards equity and fairness (ATEF), probability of auditing (POA), tax knowledge and awareness (TKA) and penalty and fines (PF). The remaining $38.81 \%$ is affected by variables that are not included in the model called extraneous variable $(\varepsilon v)$ or error term. The likelihood ratio chi-square of 194.91 with a p-value of 0.0000 shows that, the model as a whole is statistically significant. This implies the fitness of the model. The coefficient of the variable tells us by how much the independent variable affects the dependant variable.

The following table shows the marginal effect after logit that is helpful to interpret the logit result. 
Table 2. Marginal effects after logit.

\begin{tabular}{|c|c|c|c|c|c|c|c|}
\hline \multicolumn{8}{|c|}{$y=\operatorname{Pr}(T C)($ predict $)=.20160515$} \\
\hline Variable & $\mathrm{dy} / \mathrm{dx}$ & Std. Err. & $\mathbf{Z}$ & $\mathbf{P}>|\mathbf{z}|$ & [95\%C.I.] & & $\mathbf{X}$ \\
\hline AAT & $-7.81 e-07$ & .00000 & -0.25 & 0.805 & $-7.0 \mathrm{e}-06$ & $5.4 \mathrm{e}-06$ & 21871.4 \\
\hline FS & -.1478981 & .03689 & -4.01 & 0.000 & -.220193 & -.075603 & 3.62917 \\
\hline LTPP & -.1922246 & .03418 & -5.62 & 0.000 & -.259221 & -.125228 & 4.90417 \\
\hline POA & .0126407 & .03212 & 0.39 & 0.694 & -.050306 & .075587 & 1.98333 \\
\hline ATEF & .0031622 & .02823 & 0.11 & 0.911 & -.05216 & .058484 & 3.2625 \\
\hline TKA & .117608 & .03301 & 3.56 & 0.000 & .052913 & .182303 & 2.75833 \\
\hline PF & .0588215 & .02842 & 2.07 & 0.038 & .003115 & .114528 & 2.88333 \\
\hline
\end{tabular}

Source: stata 10

From the above table the marginal effect $(\mathrm{dy} / \mathrm{dx})$ result shows the degree to which the taxpayers comply with tax. Therefore, when other factors being constant; as the assessed amount of tax increased by one birr the probability to comply tax is reduced by $0.0000007 \%$ this is just insignificant. As the family size of the taxpayer increased by one person; the probability to comply with tax is decreased by $14.79 \%$. Similarly, when the remaining variables being constant; as the taxpayer pays tax for one more additional period, the probability of tax payers to comply with tax will be diminished by $19.22 \%$. Taxpayers that are audited by the revenue authority are more likely to comply with tax laws than others who are not audited. A taxpayer who treats the tax system as fair is more likely to pay their tax liability than others who treats as unfair. Similarly, taxpayers with good tax knowledge and awareness are more likely to comply with tax than others who haven't tax knowledge and awareness. Besides, taxpayers who treat the penalties and fines as high are more likely to comply with tax than others.

Model test

1. Multicolinearity test

In the construction of the model, it may happen that two or more variables giving rise to the same piece of information are included, that is, we may have redundant information or unnecessarily included related variables. In order to test multicolinearity between variables the researcher used the variance inflation factor (VIF) of each variable. The variance inflection factor reflected in the following table:

Table 3. Variance inflation factor.

\begin{tabular}{lll}
\hline Variables & VIF & $\mathbf{1 / V I F}$ \\
\hline ATEF & 1.58 & 0.633882 \\
FS & 1.56 & 0.641157 \\
TKA & 1.49 & 0.673297 \\
AAT & 1.47 & 0.678634 \\
LTPP & 1.45 & 0.691051 \\
PF & 1.08 & 0.925817 \\
POA & 1.03 & 0.968457 \\
Mean VIF & 1.38 & \\
\hline
\end{tabular}

Source: stata 10

As reflected in table 3 , all continuous variables in the regression are relevant and multicolliniarity is not there since the variable inflation factor for each variable is less than the cutoff point 10 .

2. Heteroskedasticity test

To test the hetroskedasticty of variables the researcher used Breusch-pagan test.

This test tells us that the variance remains constant for all variables. The result reflected as follows.

Breusch-Pagan / Cook-Weisberg test for Heteroskedasticity

Ho: Constant variance

Variables: fitted values of tc

$$
\operatorname{chi} 2(1)=1.19
$$

Prob $>$ chi $2=0.2755$

The above test (breusch-pagan/cook-Weisberg) shows that the absence of hetroskedasticity since chi2 is greater than of 0.05 .

\subsection{Hypothesis Testing}

Based on the formulated hypothesis in chapter one of the study, the researcher tests to show the effects of the independent variables on dependent variable.

Hal: Assessed amount of tax has a significant effect on the level of tax compliance

From table 1, the result of the study shows that, assessed amount of $\operatorname{tax}(\beta 1=-0.000000485)$ has a negative and insignificant effect on tax compliance since $p>0.05$. Hence, hypothesis $\mathrm{Hal}$ is rejected because the p-value for the variable is greater than 0.05 . This result provides evidence as the tax liability increase the level of tax compliance increases but not significant.

Ha2: Family size has a significant effect on tax 


\section{compliance}

The result of the study regarding to family size $(\beta 2=-$ 0.92 ) has negative and significant relationships with the level of tax compliance since $\mathrm{p}<0.05$. Therefore hypothesis $\mathrm{H} 2$ is accepted. This implies as the family size increase in number the willingness of taxpayers to pay their tax liability is decreased, because when the family size increases the household consumption also increases and then the amount of money to be saved is decreased. Due to this taxpayers are motivated to evade tax and increase their income level.

Ha3: The length of tax payment period has a significant effect on the level of tax compliance

The regression output regarding to length of tax payment period $(\beta 3=-1.19)$ has a negative and significant effect on the level of tax compliance with p-value of 0.000 which is less than 0.05 . so, hypothesis Ha3 is accepted. This tells us, as the tax payers are experienced for many years in paying tax the interest to pay the tax liability voluntarily is decreased.

Ha4: attitudes of taxpayers towards equity and fairness has a significant on tax compliance

The relationships of tax compliance regarding to attitudes towards equity and fairness $(\beta 4=0.019)$ is positive but not significant because $\mathrm{p}$ value for the variable is greater than that of the bench mark $p>0.05$. Thus alternative hypothesis four (Ha4) is rejected. This means that when taxpayers feel the tax system fair and equitable the willingness to pay tax is also increased. On the other hand when taxpayers treat the tax system as unfair and inequitable their willingness also decreased. But the effects of this variable on the level of tax compliance is not much or insignificant. The result is consistent with the study [12].

Ha5: probability of auditing has a significant effect on the level of tax compliance

The results of the probability of auditing $(\beta 5=0.78)$ has a positive and insignificant relationship since $p$-value of 0.699 for the variable is greater than 0.05 . Therefore, alternative hypothesis five (Ha5) is rejected. The result supported the studies $[16,17,18,19,20]$, and [21]. They found that, a higher probability of being audited or inspected motivates taxpayers to be more compliant. The implication is that, as auditing of taxpayers activity by ERCA Nekemte branch increased, the probability to pay their tax liability without any enforcement also increased, but not that much. However, the studies [22], and [6] found that probability of auditing has a negative influence on tax compliance.

Ha6: Tax knowledge and awareness has a significant effect on tax compliance

The result of this study regarding to the effect of tax knowledge and awareness on the level of compliance $(\beta 6=0.73)$ is positive and significant with $p$-value of 0.000 , which is less than the benchmark p-value of 0.05 . Therefore the hypothesis formulated in chapter one, alternative hypothesis six (Ha6) is accepted. The result tells us, as the taxpayers have knowledge and awareness about tax and its laws, rules and regulations the probability to comply with tax is also increased. The finding is consistent with many of researches conducted in tax compliance viz. [23, 24, 6, 25].

Ha7: Penalty and fines has a significant influence on tax compliance level

The finding of the study with regard to the seventh explanatory variable on tax compliance shows $(\beta=0.365)$ is positive and significant with $\mathrm{p}$-value of 0.032 which is less than the cutoff point $\mathrm{p}$-value 0.05 . This implies penalty and fines by ERCA Nekemte branch encourages taxpayers to comply with tax law. The result is consistent with the finding of the study [16], the higher the penalty the greater the discouragement for potential tax evasion and encourages tax compliance. If the taxpayers are aware of the offences they are committing when evading tax and the consequences of being non compliant taxpayers, reduce their tendency to evade tax.

\section{Conclusions}

Depending on the results which are presented, analyzed and interpreted in chapter four the following conclusions are made.

1) The finding of this study shows the effect of family size on the tax compliance behavior is negative. This implies when the family size of the taxpayers are higher the willingness to pay tax is decreased. It is resulted from as the taxpayers family size increased the consumption also goes up; this in return results a decrement in saving. Finally, this motivates taxpayers to evade tax.

2) The study found that length of tax payment period has a significant negative influence on the level of compliance. This reflects when the taxpayer paid tax for many years the probability to pay tax voluntarily without enforcement by ERCA is decreased. the reason for this is that

3) The results of this study regarding to the influences of tax knowledge and awareness on the compliance behavior of taxpayers is positive and significant. Greater parts of the respondents haven't a knowledge and awareness regarding to the tax laws rules and directives. This implies awareness creation by revenue authority encourages the taxpayer to pay their assessed amount of tax to the government regardless of enforcement by tax authority. Similarly taxpayers who have knowledge regarding to tax and its importance are voluntary to comply with tax.

4) The study also found that tax penalty and fines by revenue authority significantly determines the compliance behavior of taxpayer. 


\section{Appendix}

I. Regression results

$\begin{array}{llll}\text { Logistic regression } & \text { Number of obs } & & 240 \\ & \text { LR chi2 (7) } & = & 194.91 \\ \text { Log 1ikelihood }=-61.820241 & \text { Prob Chi2 } & = & 0.0000 \\ & \text { Pseudo R2 } & = & 0.6119\end{array}$

\begin{tabular}{r|rrrrrr}
\hline tc & Coef. & Std. Err. & $z$ & P $>|z|$ & [95\% Conf. Interva1] \\
\hline aat & $-4.85 \mathrm{e}-06$ & .0000196 & -0.25 & 0.805 & -.0000433 & .0000336 \\
fs & -.9188473 & .2279787 & -4.03 & 0.000 & -1.365677 & -.4720173 \\
1tpp & -1.194234 & .2164324 & -5.52 & 0.000 & -1.618434 & -.7700345 \\
atef & .0196455 & .1754176 & 0.11 & 0.911 & -.3241667 & .3634577 \\
poa & .0785329 & .1998548 & 0.39 & 0.694 & -.3131752 & .4702411 \\
tka & .7306635 & .1808085 & 4.04 & 0.000 & .3762853 & 1.085042 \\
pf & .3654407 & .1706109 & 2.14 & 0.032 & .0310494 & .6998319 \\
_cons & 4.63226 & 1.480446 & 3.13 & 0.002 & 1.730639 & 7.533882 \\
\hline
\end{tabular}

II. Mariginal effect after logit

\begin{tabular}{|c|c|c|c|c|c|c|c|c|}
\hline \multicolumn{9}{|c|}{$\begin{aligned} \text { Margina1 effects after logit } \\
\mathrm{y}=\operatorname{Pr}(\mathrm{tc}) \text { (predict) } \\
=.20160515\end{aligned}$} \\
\hline variable & $\mathrm{dy} / \mathrm{dx}$ & Std. Err. & $z$ & $\mathrm{P}>|\mathrm{z}|$ & {[} & $95 \%$ & C.I. & $x$ \\
\hline $\begin{array}{r}\text { aat } \\
f s \\
1 \text { tpp } \\
\text { poa } \\
\text { atef } \\
\text { tka } \\
\text { pf }\end{array}$ & $\begin{array}{r}-7.81 e-07 \\
-.1478981 \\
-.1922246 \\
.0126407 \\
.0031622 \\
.117608 \\
.0588215\end{array}$ & $\begin{array}{l}.00000 \\
.03689 \\
.03418 \\
.03212 \\
.02823 \\
.03301 \\
.02842\end{array}$ & $\begin{array}{r}-0.25 \\
-4.01 \\
-5.62 \\
0.39 \\
0.11 \\
3.56 \\
2.07\end{array}$ & $\begin{array}{l}0.805 \\
0.000 \\
0.000 \\
0.694 \\
0.911 \\
0.000 \\
0.038\end{array}$ & $\begin{array}{l}-7 \\
-. \\
-. \\
-. \\
- \\
.\end{array}$ & $\begin{array}{l}5 e-06 \\
20193 \\
5221 \\
50306 \\
5216 \\
2913 \\
3115\end{array}$ & $\begin{array}{r}5.4 \mathrm{e}-06 \\
-.075603 \\
-.125228 \\
.075587 \\
.058484 \\
.182303 \\
.114528\end{array}$ & $\begin{array}{r}21871.4 \\
3.62917 \\
4.90417 \\
1.98333 \\
3.2625 \\
2.75833 \\
2.88333\end{array}$ \\
\hline
\end{tabular}

III. VARIANCEINFLATION FACTOR

\begin{tabular}{|c|c|c|}
\hline Variable & VIF & 1/VIF \\
\hline $\begin{array}{r}\text { atef } \\
\text { fs } \\
\text { tka } \\
\text { aat } \\
\text { 1tpp } \\
\text { pf } \\
\text { poa }\end{array}$ & $\begin{array}{l}1.58 \\
1.56 \\
1.49 \\
1.47 \\
1.45 \\
1.08 \\
1.03\end{array}$ & $\begin{array}{l}0.633882 \\
0.641157 \\
0.673297 \\
0.678634 \\
0.691051 \\
0.925817 \\
0.968457\end{array}$ \\
\hline Mean VIF & 1.38 & \\
\hline
\end{tabular}

\section{HETROSKEDASTICITY TEST}

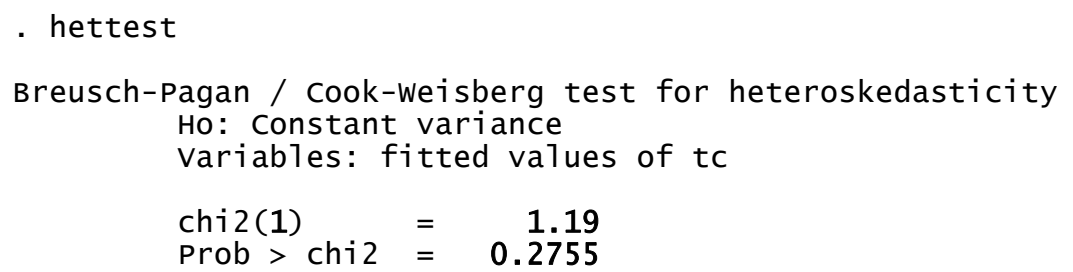




\section{References}

[1] Misrak, T. (2011). Ethiopian tax accounting principle and practice. Addis Ababa, Ethiopia.

[2] Serkan B., Tamer, B., \& Mohdali, R. (2016). The impact of religiosity on tax compliance among Turkish self-employed taxpayers, Religions 7 (2). pp. 37-39.

[3] Marti, L. O. (2010). Taxpayers attitudes and tax compliance behavior in Kenya. African Journal of Business \& Management.

[4] Marziana, H., Mohamed, N., Orkhazimah, A., \& Mohamed, S. D. (2010). Perceptions of taxpayers with level of compliance: A comparison in the east coast region, Malaysia. Journal of Global Business and Economics, 1 (1), 241-257.

[5] James, S.,\& Alley, C. (2004). Tax compliance cost, University of Exeter Business School Streatham, United Kingdom.

[6] Niway, A. A.,\& Wondwossen, J. (2016). Determinants of voluntary tax compliance: Evidence from SNNPRs, Ethiopia. International journal of science and research (IJSR), Vol. 5, Issue 12, December 2016.

[7] Kirchler, E. (2007). The economic psychology of tax behavior. Cambridge: Cambridge University Press.

[8] Ojochogwu, W. A.,\& Stephen, A. O. (2012). Factors that affect tax compliance among Small and medium enterprises (SMEs) in North Central Nigeria.

[9] Suresh, V., \& Srinivas, G. (2012). Factors that influence rental taxpayers compliance with tax system: An empirical study of Mekelle City, Ethiopia.

[10] Abubakari, \& Christopher. (2013). Evaluating taxpayers attitude and its influnce on tax compliance decisions in tamale, Ghana.

[11] Nelson, M. (2014). The impact of personal tax knowledge and compliance costs on tax compliance behavior of SMEs in Zimbabwe. Elite Research Journal of Accounting and Business Management Vol. 2 (3), July 2014.

[12] Tilahun, A., \& Yiedersal, D. (2014). Determinants of tax compliance behavior in Ethiopia: The case of Bahirdar City Taxpayers, Vol. 5 No. 15, 2014.
[13] Ketema, D. W. (2016). Factors affecting tax compliance of small and medium business profit taxpayers in Addis Ababa.

[14] Daniel, M., \& Shaik, A. M. P. (2017). Factors affecting voluntary compliance of category ' $\mathrm{C}$ ' taxpayers attitude of Arbaminch, SNNPR, Ethiopia. International Journal of scientific and research publications, Vol. 7, issue 6.

[15] Yamane, T. (1967). Statistics, an introductory analysis (2nd ed.). New York, NY.

[16] Allingham, M. G., \& Sandmo, A. (1972). Income tax evasion: A theoretical analysis. Journal of Public Economics, 1 (3-4), pp. 323-38.

[17] Beron, K. L., Tauchen, H. V., \& Witte, A. D. (1988). A structural equation model for taxcompliance and auditing, NBER working paper no 2556, National Bureau of Economic Research.

[18] Jackson. B. R., and Milliron, V. C. (1986). Tax compliance research: Findings, problems, and prospects. Journal of Accounting Literature, 5, pp. 125-65.

[19] Andreoni, J., Errad, B., \& Feinstein, J. (1998). Tax Compliance, Journal of Economic Literature, Vol. 36, pp. 818 -819 .

[20] Dubin, J. (2004). Criminal Investigation Enforcement Activities and Taxpayer Noncompliance. IRS Research Conference. Washington D. C.

[21] Taylor and Francis Journals, vol. 9, No. 3, pp. 281-289.

[22] J. S. Kramer. (1991). The Logit Model for Economists. Edward Arnold Publishers, London,; and G. S. Maddala, op. cit.

[23] Kirchler, E., Hoelzl, E., \& Whal, I. (2008). Enforced versus voluntary tax compliance: The "slippery slope" framework. Journal of Economic Psychology, Issue 29 (2008).

[24] M. R. Palil. (2010). Tax knowledge and tax compliance determinants in self-assessment system in Malaysia.

[25] Samuel, A., \& Viswanadham, P. (2016). An assessment of business income taxpayers tax knowledge, tax complexity, and tax compliance: A Case of Amhara Regional State ofEthiopia. International journal of Science and Research (IJSR) ISSN, pp. 2319-7064. 